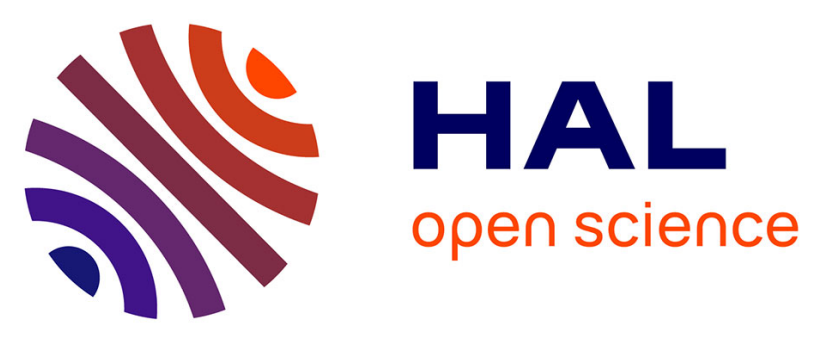

\title{
A concise guide to polymer nomenclature for authors of papers and reports in polymer science and technology (IUPAC Technical Report)
}

Philip Hodge, Karl-Heinz Hellwich, Roger C. Hiorns, Richard G Jones, Jaroslav Kahovec, Christine K Luscombe, Malcolm D Purbrick, Edward S Wilks

\section{To cite this version:}

Philip Hodge, Karl-Heinz Hellwich, Roger C. Hiorns, Richard G Jones, Jaroslav Kahovec, et al.. A concise guide to polymer nomenclature for authors of papers and reports in polymer science and technology (IUPAC Technical Report). Pure and Applied Chemistry, 2020, 92 (5), pp.797-813. 10.1515/pac2018-0602 . hal-03043625

\section{HAL Id: hal-03043625 \\ https: / hal-univ-pau.archives-ouvertes.fr/hal-03043625}

Submitted on 7 Dec 2020

HAL is a multi-disciplinary open access archive for the deposit and dissemination of scientific research documents, whether they are published or not. The documents may come from teaching and research institutions in France or abroad, or from public or private research centers.
L'archive ouverte pluridisciplinaire HAL, est destinée au dépôt et à la diffusion de documents scientifiques de niveau recherche, publiés ou non, émanant des établissements d'enseignement et de recherche français ou étrangers, des laboratoires publics ou privés.

\section{(1) (1) $\$$}

Distributed under a Creative Commons Attribution - NonCommercial - NoDerivatives 44.0 


\section{IUPAC Technical Report}

\section{Philip Hodge*, Karl-Heinz Hellwich, Roger C. Hiorns, Richard G. Jones, Jaroslav Kahovec, Christine K. Luscombe, Malcolm D. Purbrick and Edward S. Wilks A concise guide to polymer nomenclature for authors of papers and reports in polymer science and technology (IUPAC Technical Report)}

https://doi.org/10.1515/pac-2018-0602

Received June 18, 2018; accepted March 27, 2019

Abstract: This brief Technical Report summarizes the key points on the nomenclature of macromolecules and polymers.

Keywords: polymer nomenclature; source-based nomenclature; structure-based nomenclature.

\section{International union of pure and applied chemistry (IUPAC) recommendations}

It is the goal of the IUPAC Polymer Division and the IUPAC Division of Chemical Nomenclature and Structure Representation to improve communication between polymer scientists and chemists and scientists in general by recommending unambiguous, standardized, and universally understood names and structure representations of polymers. The following is a concise guide to polymer nomenclature based on official IUPAC recommendations. The main points carry hyperlinks to the source documents. The colours of the hyperlinks correspond to the colours of the IUPAC books, i.e. gold for the Gold Book, purple for the Purple Book (polymers), blue for the Blue Book (organic chemistry), etc. A more detailed treatment can be found in the Purple Book [1]: a two-page Brief Guide is also available on-line [2].

Article note: Sponsoring body: IUPAC Polymer Division: see more details on page 812. This manuscript was prepared in the framework of IUPAC project 2008-020-1-400.

*Corresponding author: Philip Hodge, Chemistry Department, University of Manchester, M13 9PL, UK, e-mail: Philip.Hodge@manchester.ac.uk

Karl-Heinz Hellwich: Beilstein-Institut zur Förderung der Chemischen Wissenschaften, Trakehner Str. 7 - 9, 60487 Frankfurt, Germany. https://orcid.org/0000-0002-4811-7254

Roger C. Hiorns: CNRS/Univ Pau and Pays Adour, Institut des Science Analytiques et Physico-Chimie pour l'Environnement et les Materiaux, UMR 5254, 64000 Pau, France

Richard G. Jones: School of Physical Sciences, University of Kent, Canterbury, CT2 7NH, UK Jaroslav Kahovec: Institute of Macromolecular Chemistry, Academy of Sciences of the Czech Republic, Heyrovsky Sq. 2, 16206 Praha 6, Czech Republic

Christine K. Luscombe: University of Washington, Seattle, USA

Malcolm D. Purbrick: Brighton, East Sussex, UK

Edward S. Wilks: 113 Meriden Drive, Canterbury Hills, Hockessin, DE 19707, USA 


\subsection{Introduction}

The primary goal of chemical nomenclature is to identify chemical substances by their names so that scientists can communicate information about them without the need for representations of their chemical structures. This goal is especially important in connection with the ever-increasing growth of electronic databases.

The terms polymer and macromolecule are often used as if they were interchangeable, but this is incorrect. A polymer is a substance composed of macromolecules. Unlike low-molar-mass substances, in the vast majority of cases polymers consist of macromolecules that do not have completely uniform structures. A polymer is generally a mixture of macromolecules, each of which can differ from others in the same sample in its chain length and/or detailed structural arrangement, such as irregularities in the orientation of the monomer unit, end-groups, and in the locations and lengths of any branches.

The reaction involving polymerization of a monomer such as vinyl chloride (chloroethene) is generally depicted as<smiles>C=CCC(Cl)Cl</smiles>

Note that in the polymer formula, ' $n$ ' is a variable indicating multiple repetitions and is therefore italicized. Wavy lines, commonly drawn perpendicularly to free bonds and conventionally used to indicate free valences [3], are not used in graphical representations of polymers [4]. Thus, polymer structures use square brackets; partial structures use wavy lines.

This graphical representation is ideal rather than true. It gives no indication that the polymer contains many macromolecules with different chain lengths. It assumes that all the repeating units are connected in an identical fashion, namely 'head-to-tail'. In a real polymer, each macromolecule will almost always contain some 'head-to-head' dyads and some 'tail-to-tail' dyads in addition to 'head-to-tail' dyads. The precise amounts and sequences of these are often unknown.

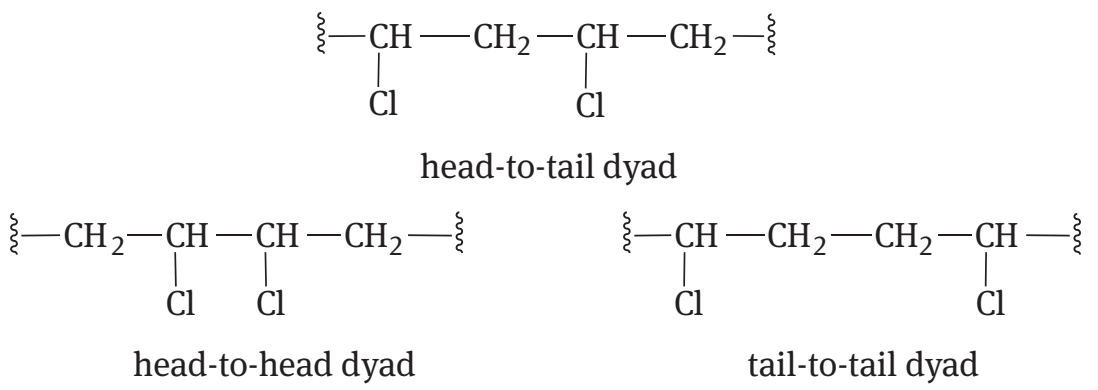

With copolymers, the structure's complexity and uncertainty increases further, because the order of the constitutional units derived from the different monomers can vary within a chain. The monomers propene and but-1-ene, for example, can be combined in different ways to give copolymers within which they are distributed randomly, statistically, alternately, as blocks of identical monomer units, which might or might not be periodic, or in some other arrangement, such as grafts. Furthermore, both constitutional units derived from these monomers contain a carbon atom to which four different groups are attached, i.e. they are chiral. This means that each monomer unit can also exist in two different configurations. Because full details of the structural irregularities are not usually known, the nomenclature recommendations generally apply to representations which are idealized or theoretical.

A polymer can be named in one of two ways. 'Source-based Nomenclature' can be used when the monomer(s) is/are known. 'Structure-based Nomenclature' can be used when the constitutional units of the polymer are defined. These two systems are considered separately below. 


\section{IUPAC recommendations for source-based nomenclature of polymers}

\subsection{Nomenclature for homopolymers}

A homopolymer, as the name implies, is a polymer derived from just one type of monomer. This may be either the actual monomer used in the polymerization, e.g. styrene, or it may be an apparent monomer as a consequence of the chemical modification of an original constitutional unit after polymerization. A common example of the latter is the vinyl alcohol unit formed by the hydrolysis of a vinyl acetate unit.

In source-based nomenclature of homopolymers, the polymers are named by writing the prefix 'poly', followed by the name of the actual or apparent monomer in accordance with IUPAC rules for nomenclature of organic chemistry [5] or, if appropriate, the IUPAC rules for inorganic nomenclature [6, 7]. Names of monomers that include substituents, or contain locants, or are two-word names, or might otherwise be ambiguous are parenthesized, e.g. poly(chlorostyrene) is used to distinguish the intended polymer name from a small molecule that is multi-substituted with chloro substituents. If the monomer name is one word and there are no locants quoted, parentheses are not essential. They should, however, be used when it is necessary to avoid confusion, e.g. to distinguish the polymer poly(oxolane) (= polytetrahydrofuran) from the class name polyoxolane used for five-membered rings with more than one oxygen atom. Some examples of homopolymer names are given in Table 1.

Table 1: Examples of homopolymer names.

\begin{tabular}{llll}
\hline Polyacrylonitrile & Poly(1,1-difluoroethene) & Poly(methacrylic acid) & Poly(vinyl acetate) \\
Poly(4-bromostyrene) & Poly(ethyl acrylate) & Poly(methyl methacrylate) & Poly(vinyl alcohol) \\
Poly(but-1-ene) & Polyethene $^{\text {a }}$ & Poly(propyl vinyl ether) & Poly(vinyl fluoride) \\
\hline
\end{tabular}

aAlso known as polyethylene, which is a retained traditional name and the preferred polymer name (see Section 4).

\subsection{Nomenclature for copolymers}

Any polymer derived from more than one type of monomer is referred to as a copolymer [8-10]. As in the case of homopolymers, each constitutional unit in the copolymer may arise directly from an actual monomer, i.e. a reactant, or from a new unit derived from a monomer unit after polymerization.

Copolymers are named by writing the prefix 'poly' followed by the names of the monomer units. An infix, called a connective, is placed between the names of the monomers or blocks, respectively, to indicate the arrangement of units within the chains. The connectives are written in italics, as they describe the structure

Table 2: IUPAC copolymer classification in source-based nomenclature [8].

\begin{tabular}{lll}
\hline Copolymer structure & Connective & Nomenclature \\
\hline Unspecified or unknown & $-c o-$ & poly(A-co-B) \\
Random (has a Bernoullian distribution) & - ran- & poly(A-ran-B) \\
Statistical (obeys known statistical laws) & - stat- & poly(A-stat-B) \\
Alternating (for two monomer units) & - alt- & poly(A-alt-B) \\
Periodic (regular arrangement of constitutional units) & - per- & poly(A-per-B-per-C) \\
Block (linear block arrangement) & - block- & polyA-block-polyB \\
Graft (side chains polyB linked to main chains polyA) & - graft- & polyA-graft-polyB \\
\hline
\end{tabular}


Table 3: Examples of source-based names for copolymers.

\begin{tabular}{ll}
\hline Poly(methacrylonitrile-co-propene) & Polyacrylonitrile-block-poly(buta-1,3-diene)-block-polystyrene ${ }^{\mathrm{a}}$ \\
Poly[(butyl acrylate)-ran-(ethyl acrylate)] & Poly(oxirane-per-tetrahydrofuran) \\
Poly(ethene-stat-propene-stat-styrene) & Polyisoprene-graft-poly(methacrylic acid) ${ }^{\mathrm{b}}$ \\
Poly[(adipic acid)-alt-(butane-1,4-diol)] & \\
\hline
\end{tabular}

aSystematic and retained traditional names (vide infra) of monomers can be used. For example, polymethacrylonitrile-block-poly(buta-1,3-diene)-block-polystyrene may also be named poly(prop-2-enenitrile)-block-poly(buta-1,3-diene)-block-poly(ethenylbenzene).

${ }^{\mathrm{b}}$ The first name component is that of the backbone.

and not the constituents of the polymer. Table 2 lists the connectives commonly used to indicate the arrangement of monomer units.

Table 3 contains some names of common copolymers. Note that IUPAC recommends the alphabetization of monomer names within a copolymer name, except where a fixed sequence of monomer units needs to be named [8]. When more than one acceptable name exists for a given monomer, several names are possible for a copolymer.

Note that when multiple sets of parentheses, square brackets or braces are required, IUPAC recommends the use of parentheses for the innermost, then square brackets and then braces, thus $\{[(\ldots)]\}$. If further nesting is required, this cycle is repeated, i.e. $\{[(\{[(\ldots)]\})]\}$, etc.

\subsection{Nomenclature for non-linear polymers and polymer assemblies}

A 1997 IUPAC document covers "Source-based Nomenclature for Non-linear Macromolecules and Macromolecular Assemblies”, such as branched, comb, cyclic, graft, network, and star polymers, as well as polymer assemblies, such as interpenetrating polymer networks, polymer blends, and polymer-polymer complexes $[1,11]$. The polymers in these classes, together with their connectives, are given in Table 4, while examples of their use are shown in Table 5. Note that the terms shown may be used as connectives or prefixes to designate the features present. As before, the connective or prefix is italicized, as they describe the structure rather than the chemical constituents.

Table 4: Connectives or prefixes for non-linear polymers and polymer assemblies [11].

\begin{tabular}{ll}
\hline Type of structure & Connective or prefix \\
\hline Branched (type unspecified) & branch \\
Branched with branch point of functionality $f$ & $f$-branch \\
Long-chain branched & l-branch \\
Short-chain branched & sh-branch \\
Comb(like) & comb \\
Crosslinked & $v$ (italic Greek nu) \\
Cyclic & cyclo \\
Network & net \\
Micronetwork & $\mu$-net \\
Interpenetrating polymer network & ipn \\
Semi-interpenetrating polymer network & sipn \\
Polymer blend & blend \\
Polymer-polymer complex & compl \\
Star & star \\
Star with $f$ arms & f-star \\
\hline
\end{tabular}


Table 5: Examples of the use of connectives and/or prefixes for non-linear polymers.

\begin{tabular}{ll}
\hline Polymer name [11] & Polymer structure \\
\hline Poly(acrylic acid)-comb-polyacrylonitrile & $\begin{array}{l}\text { Comb polymer with a poly(acrylic acid) backbone and } \\
\text { polyacrylonitrile arms } \\
\text { Comb polymer with unspecified backbone composition and } \\
\text { statistical ethene/ethenyl chloride copolymer arms }\end{array}$ \\
Poly(buta-1,3-diene)-comb-poly(ethene-co-propene) & $\begin{array}{l}\text { Comb polymer with poly(buta-1,3-diene) backbone and } \\
\text { branches of poly(ethene-co-propene) }\end{array}$ \\
& Star polymer with arms of polyA, polyB, polyC and polyD \\
star-(polyA;polyB;polyC;polyD) & Star polymer with every arm comprising triblock chains polyA- \\
star-(polyA-block-polyB-block-polyC) & block-polyB-block-polyC \\
& Star polymer with poly(oxirane) arms \\
star-Poly(ethylene oxide) & A blend of polyethylene and poly(but-1-ene) \\
Poly(but-1-ene)-blend-polyethylene & A blend of poly(methacrylic acid) and poly(methyl methacrylate) \\
Poly(methacrylic acid)-blend-poly(methyl methacrylate) & A network of crosslinked poly(4-methylstyrene) \\
net-Poly[(4-methylstyrene)- $v$-(1,4-diethenylbenzene)] & Network formed by crosslinking poly[(maleic anhydride)-alt- \\
net-Poly[(maleic anhydride)-alt-styrene]- $v$-poly(propylene & styrene] with poly(propylene oxide) \\
oxide) & Polystyrene network penetrated on a molecular scale by \\
(net-polystyrene)-sipn-poly(vinyl chloride) & poly(vinyl chloride) \\
&
\end{tabular}

\section{IUPAC recommendations for structure-based nomenclature of polymers}

\subsection{Structure-based nomenclature for regular single-strand organic polymers $[12,13]$}

The smallest constitutional unit whose repetition generates a regular single-strand polymer chain is called the constitutional repeating unit (CRU). Often, several CRUs can be written for a polymer chain (see below). One of these, the preferred CRU, is used as the basis for the structure-based nomenclature of a polymer [12, 13]. Single-strand polymers consisting of the preferred CRUs in a single sequential arrangement are therefore named in the following manner: poly(constitutional repeating unit).

Before a preferred CRU can be named, it must be selected out of the several possible CRUs that can be identified, i.e. the subunits of which it is composed must be determined and must be oriented, i.e. written in a manner that follows the rules developed by IUPAC. These are discussed below.

For most polymer structures, the CRU can be written in more than one direction. Thus, for the simple homopolymer shown below, there are two possible CRUs that can be identified.<smiles>CCC(F)CC(F)CC(F)I</smiles>

Of the following two CRUs, that on the left is preferred, because it has a lower locant for the fluoro substituent.<smiles>CC(F)CCC(F)I</smiles>

In more complex polymers, such as

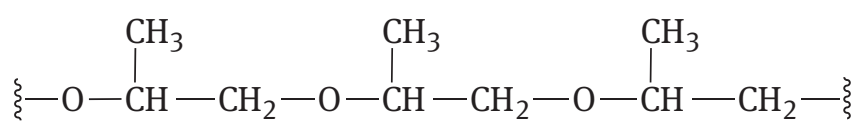


there are more possible CRUs, in this case the following six CRUs:<smiles>CCC(C)OC</smiles><smiles>COCC(C)C</smiles><smiles>CCOC(C)C</smiles><smiles>CCC(C)OC</smiles><smiles>COCC(C)C</smiles><smiles>CCOCC</smiles>

Just one of these must be selected as the preferred one, and the preferred CRU must be oriented with the most senior subunit to the left before it can be named correctly. The complete process of identifying, orienting, and naming a CRU involves three steps, which must be carried out in the following order.

Step A: Identifying the CRU: This is best achieved by drawing a portion of the polymer chain sufficient in length as to show the structural repetition. The smallest repeating portion is a CRU.

Step B: Orienting the CRU: When a CRU is unsymmetrical, which is almost always the case, there might be several ways in which it can be orientated. Selecting the preferred way can be a challenging step. This selection involves the identification of the subunits that make up each of the possible CRU structures. These subunits are the largest divalent groups that can be named using IUPAC nomenclature of organic [5] and inorganic compounds [6, 7], examples of which are given in Table 6. Once the subunits have been identified, the correct order is determined using the shortest path from the most senior subunit to the next-most senior. The preferred CRU will then be that with the lowest possible locants for substituents. Illustrated guidelines are given in Section 3.2 for the identification of most types of CRU, but comprehensive coverage of all the rules $[12,13]$ for selecting the preferred CRU is outside the scope of this short article.

Step C: Naming the CRU: Finally, the preferred CRU, oriented with the most senior subunit to the left, is named by citing the names of all subunits consecutively, from left to right, in accordance with the relevant IUPAC nomenclature rules, most frequently those of organic-chemical nomenclature.

\subsection{Detailed seniority rules for structure-based names of complex regular single-strand organic polymers}

When polymers have more than one subunit of the types listed in Table 6, there is a question of the seniority and direction of these subunits. The rules presented below were designed to enable the determination of: (1) seniority among subunits, i.e. which subunit is written leftmost in the complete CRU; and (2) the direction along the polymer chain in which to continue to the end of the preferred CRU.

\section{(1) Seniority}

Among the subunits that form a single-strand CRU, the seniority order is as follows: heterocycles $>$ chains consisting of hetero atoms $>$ carbocycles $>$ carbon chains.

Subunit type (a): heterocycles

Examples: piperidine-3,5-diyl thiophene-2,5-diyl 
Table 6: Examples of divalent constitutional units ${ }^{\mathrm{a}}[12]$.

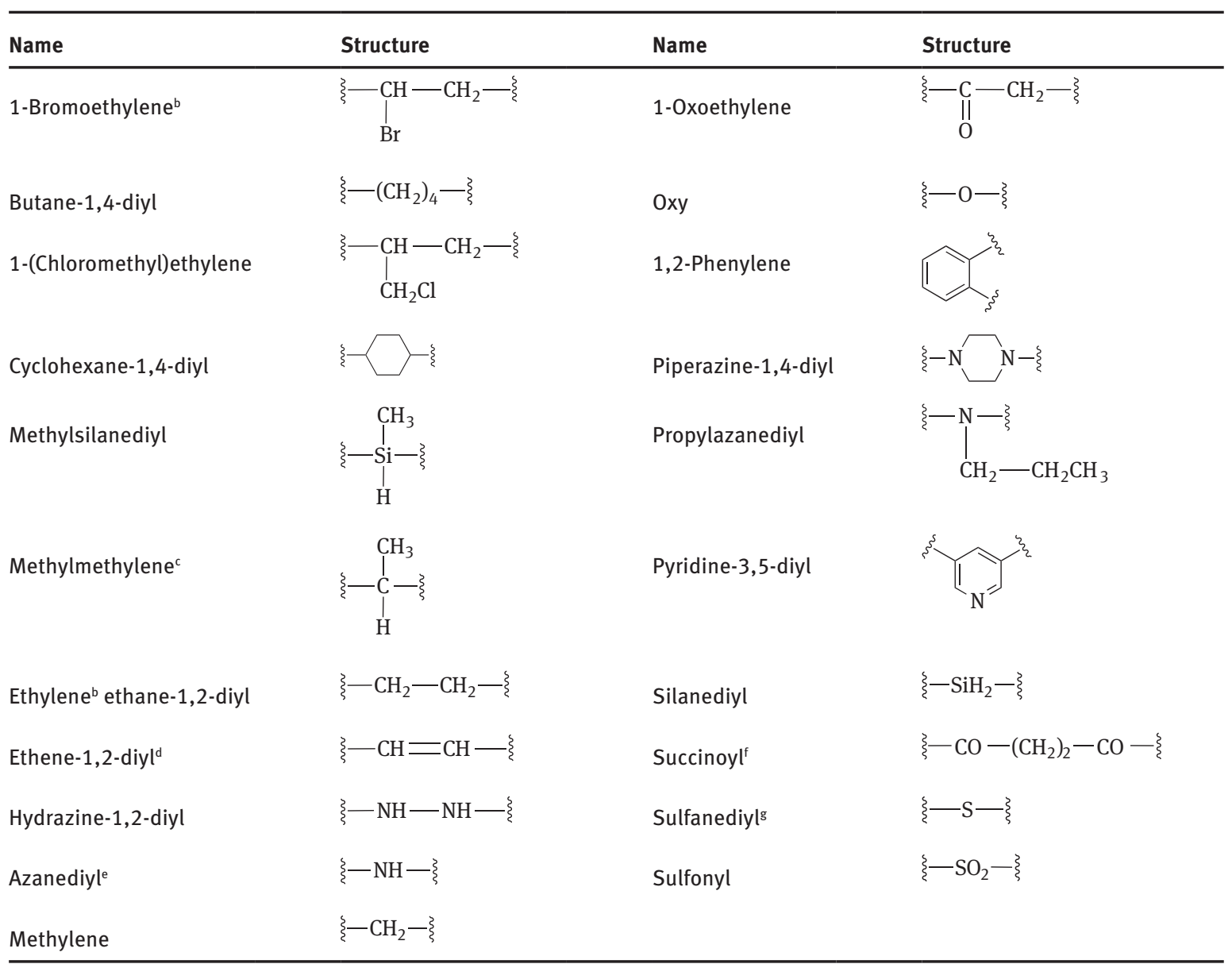

aEven when substituted, the largest subunit possible is selected for naming in accord with IUPAC nomenclature rules. Typically, ethylene is not called 'methylenemethylene' or 'dimethylene', terephthaloyl is not called 'carbonyl-1,4-phenylenecarbonyl', and $-\mathrm{CH}_{2}-\mathrm{CO}-\mathrm{CH}_{2}-\mathrm{CH}_{2}-$ is called 2-oxobutane-1,4-diyl, not 'methylenecarbonylethylene'.

${ }^{b}$ All structure-based polymer names based on 'ethylene' are preferred to the equivalent names based on the also-permitted alternative name 'ethane-1,2-diyl', e.g. 1-bromoethane-1,2-diyl.

'IUPAC no longer recommends 'ethylidene' as a name for this subunit when it is connected to two different atoms. The name 'ethane-1,1-diyl' is not used for a subunit as part of the backbone of a polymer.

'IUPAC no longer recommends the use of the former name 'vinylene' for this subunit. eIUPAC no longer recommends the former name 'imino' for this subunit.

fOther similar permitted subunit names include adipoyl, isophthaloyl, malonyl, oxalyl, phthaloyl, and terephthaloyl [12, 13]. sIUPAC no longer recommends 'thio' as a name for this subunit.

Subunit type (b): heteroatom chains

Examples: oxy

$$
\begin{aligned}
& \text { sulfanediyl } \\
& \text { disulfanediyl } \\
& \text { sulfonyl } \\
& \text { azanediyl }
\end{aligned}
$$

Subunit type (c): carbocycles

Examples: 1,3-phenylene

cyclohexane-1,3-diyl 
Subunit type (d): carbon chains

Examples: ethylene (ethane-1,2-diyl)

1-chloroethylene

propane-1,3-diyl

decane-1,10-diyl

Seniority within subunit types (a)-(d) is then determined by further rules, a selection of which is as follows.

Subunit type (a): Heterocycles.

A nitrogen-containing ring system is senior to a ring system containing any other heteroatom. If no nitrogen atom is present, the seniority follows the order indicated under Subunit type (b) below. Further descending order of seniority is determined by:

(i) the largest number of rings in the ring system;

(ii) the largest individual ring in the ring system;

(iii) the largest number of heteroatoms in the ring system;

(iv) the greatest variety of heteroatoms in the ring system.

Subunit type (b): Heteroatom chains. The order of subunit seniority follows the periodic table in the following sequence: $\mathrm{O}, \mathrm{S}, \mathrm{Se}, \mathrm{Te}, \mathrm{N}, \mathrm{P}, \mathrm{As}, \mathrm{Sb}, \mathrm{Bi}, \mathrm{Si}, \mathrm{Ge}, \mathrm{Sn}, \mathrm{Pb}, \mathrm{B}, \ldots$

Subunit type (c): Carbocycles. Seniority is determined by:

(i) the largest number of rings in the ring system;

(ii) the largest individual ring in the ring system;

(iii) the largest number of atoms common to the rings;

(iv) degree of ring saturation; an unsaturated ring is senior to a saturated one (of the same size).

Subunit type (d): For carbon chains, the descending order of seniority is determined by:

(i) chain length (longest is senior);

(ii) number of multiple bonds (largest number is senior);

(iii) number of substituents (largest number is senior);

(iv) ascending order of locants;

(v) alphabetical order of names of substituents.

The seniority rules given above are applied only to the subunits of the main chain. Substituents in mainchain subunits, whether the subunits are of type (a), (b), (c), or (d), do not control the CRU selection unless otherwise identical subunits need to be differentiated by either the number of substituents or their alphabetical order.

\section{(2) Orientation}

The preferred CRU is the one that begins with the subunit of highest seniority and continues along the chain in the direction of either (i) another occurrence of the same subunit or (ii) the subunit next in seniority. If, in (i), there is more than one further occurrence of the same subunit, the preferred path is the shorter one between the senior subunit and one of its further occurrences.

Example 1:<smiles>[3H]OC(C)C</smiles>

Application of the above criteria gives the following results. 
1. $\mathrm{O}$ is the senior subunit

2. For the substituted ethylene subunit, the preferred position for the methyl group is on the leftmost carbon atom, i.e. it is assigned the lowest possible locant when reading from left to right.

The name of the polymer is thus poly[oxy(1-methylethylene)] [14].

Example 2: Consider the following chain (henceforth hydrogen atoms and the substituents to the main chain are omitted)

$$
\{-\mathrm{O}-\mathrm{C}-\mathrm{O}-\mathrm{C}-\mathrm{C}-\mathrm{S}-\mathrm{C}-\mathrm{C}-\mathrm{O}-\mathrm{C}-\mathrm{O}-\mathrm{C}-\mathrm{C}-\mathrm{S}-\mathrm{C}-\mathrm{C}-\mathrm{O}-\mathrm{C}-\xi
$$

Identifying the CRU: This CRU has a regularly repeating eight-atom sequence. Thus, starting from one sulfur atom, for example, and proceeding along the chain in either direction as far as, but not including, the next sulfur atom results in the conclusion that the CRU contains eight atoms, two of which are oxygen atoms.

Orienting the CRU: There are no heterocycles [subunit type (a)] present, so one of the heteroatoms [subunit type (b)] must be the senior subunit. $\mathrm{O}$ is senior to $\mathrm{S}$, and therefore one of the two oxygen atoms must be selected as the senior subunit. Numbering the locations of the two oxygen atoms arbitrarily $\mathrm{O}^{1}$ and $\mathrm{O}^{2}$ gives:

$$
\left\{-\mathrm{O}-\mathrm{C}-\mathrm{O}-\mathrm{C}-\mathrm{C}-\mathrm{S}-\mathrm{C}-\mathrm{C}-\mathrm{O}^{2}-\mathrm{C}-\mathrm{O}-\mathrm{C}-\mathrm{C}-\mathrm{S}-\mathrm{C}-\mathrm{C}-\mathrm{O}^{2}-\mathrm{C}-\mathrm{H}^{1}\right.
$$

Beginning with either occurrence of $\mathrm{O}^{1}$ and proceeding along the chain in the direction of the second subunit of equal seniority, $\mathrm{O}^{2}$, as far as, but not including, a second occurrence of $\mathrm{O}^{1}$, gives two possibilities that are each eight atoms long (for this determination, reading in both directions is essential):

$$
\begin{aligned}
& \text { (1) }-\mathrm{O}^{1}-\mathrm{C}-\mathrm{C}-\mathrm{S}-\mathrm{C}-\mathrm{C}-\mathrm{O}^{2}-\mathrm{C}- \\
& \text { (2) }-\mathrm{C}-\mathrm{C}-\mathrm{S}-\mathrm{C}-\mathrm{C}-\mathrm{O}^{2}-\mathrm{C}-\mathrm{O}^{1}-
\end{aligned}
$$

According to the guidelines, the preferred path from $\mathrm{O}^{1}$ to $\mathrm{O}^{2}$ is the shorter one; therefore, sequence (2), when laterally reversed from $-\mathrm{C}-\mathrm{C}-\mathrm{S}-\mathrm{C}-\mathrm{C}-\mathrm{O}^{2}-\mathrm{C}-\mathrm{O}^{1}-$ to $-\mathrm{O}^{1}-\mathrm{C}-\mathrm{O}^{2}-\mathrm{C}-\mathrm{C}-\mathrm{S}-\mathrm{C}-\mathrm{C}-$, becomes the preferred CRU. It may be noted that beginning with either occurrence of $\mathrm{O}^{2}$ would produce the same result in this example.

The identified and oriented $\mathrm{CRU}$ is thus $-\mathrm{O}-\mathrm{C}-\mathrm{O}-\mathrm{C}-\mathrm{C}-\mathrm{S}-\mathrm{C}-\mathrm{C}-$, and including hydrogen atoms $-\mathrm{O}-\mathrm{CH}_{2}-\mathrm{O}-\mathrm{CH}_{2}-\mathrm{CH}_{2}-\mathrm{S}-\mathrm{CH}_{2}-\mathrm{CH}_{2}-$.

\section{Naming is as follows:}

1. Reading from left to right, name the subunits (see Table 6) in the order in which they occur.

2. Precede the subunit name assembly with poly and insert parentheses, brackets, and braces as necessary to avoid confusion. Subunits carrying substituents have enclosing marks.

The preferred name for this CRU, written in the style 'poly(constitutional repeating unit)', is thus poly(oxym ethyleneoxyethylenesulfanediylethylene).

Example 3: Poly[(ethylazanediyl)ethyleneazanediyl-1,3-phenylene] has the following structure:<smiles>CCN(C)CCNc1cccc(C)c1</smiles> 
The steps that result in this name are as follows.

1. One of the two nitrogen atoms is the senior subunit.

2. The substituted (tertiary) $\mathrm{N}$ is senior to the unsubstituted (secondary) $\mathrm{N}$ [see subunit type (d) (iii) above].

3. The shorter path from the senior $\mathrm{N}$ to the other $\mathrm{N}$ is via the ethylene subunit (two atoms between the two $\mathrm{N}$ atoms), not via the ring (three atoms between the two $\mathrm{N}$ atoms).

Example 4: Poly[thiophene-2,4-diyl(1-oxoethylene)oxyethylene] has the structure:

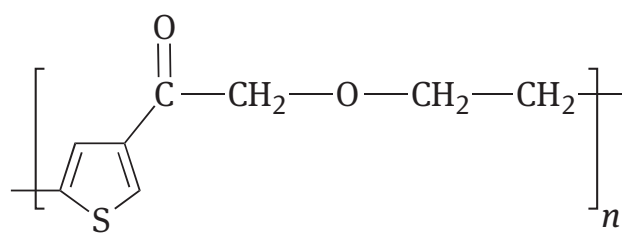

The steps that led to this orientation and name were as follows.

1. The heterocycle is the senior subunit.

2. The path length from the senior subunit to - $\mathrm{O}-$, the next senior subunit, is the same in both directions along the CRU. Criterion subunit type (d) (ii) is used to make a decision between the two paths of equal length; the substituted subunit (1-oxoethylene) is senior to the unsubstituted subunit (ethylene).

\subsection{Naming of end-groups}

Another structural feature that may need to be named is the end-groups. This is often the case when dealing with the synthesis of block copolymers.

The procedure for naming end-groups on polymers is as follows:

1. Identify, orient, and name the CRU according to the above rules.

2. Name the end-groups as substituents. Use parentheses, brackets, or both, as necessary.

3. Prefix the name of the left-hand end-group (of the correctly oriented formula) by the Greek letter $\alpha$.

4. Prefix the name of the right-hand end-group by the Greek letter $\omega$.

5. Assemble the complete name in the format:

$\alpha$-(left-hand end-group)- $\omega$-(right-hand end-group)poly(CRU)

Note that for polymers comprising symmetrical CRUs, e.g. poly(methylene), end-group names are alphabetized. The end-group that alphabetizes first is designated as the $\alpha$-end-group (see Example 5 below). For unsymmetrical CRUs in which the two end-group names are different from each other, the $\alpha$-end-group is cited first, regardless of alphabetic order (see Example 6).

Example 5: $\alpha$-Chloro- $\omega$-(trichloromethyl)poly(methylene)

$$
\mathrm{Cl}-\mathrm{CH}_{2}+\mathrm{CCl}_{n}
$$

Example 6: $\alpha$-(Trichloromethyl)- $\omega$-chloropoly(1,1-difluoroethylene)

$$
\left.\mathrm{Cl}_{3} \mathrm{C}-\mathrm{CF}_{2}-\mathrm{CH}_{2}\right]_{n} \mathrm{Cl}
$$




\subsection{Nomenclature for irregular single-strand organic polymers [15]}

The naming of constitutional units (CUs) of an irregular, single-strand organic polymer follows the rules in Section 3.1 above. The complete polymer name is constructed by combining names of individual CUs in alphabetical order, separating each pair with a solidus (oblique stroke, slash), parenthesizing or bracketing the complete expression as necessary, and adding the prefix 'poly'. The solidus is used to indicate that information is unavailable on the individual CU sequence in the polymer.

In graphical representations of these polymers, the hyphens or dashes at each end are shown within the enclosing marks. This indicates that they are not necessarily the terminal bonds of the macromolecule.

The examples in Table 7 illustrate application of these recommendations.

\subsection{Nomenclature for regular double-strand organic polymers [16]}

Every macromolecule in a double-strand polymer contains a continuous sequence of fused rings. Spiro polymers have one atom in common with adjacent rings. Ladder polymers have two or more atoms in common with each adjacent ring. As with regular single-strand polymers, a regular double-strand polymer CRU must be identified and oriented before the polymer can be named. The preferred CRU is a multivalent group in which attachment to all atoms of adjacent CRUs is cited. The CRU is named in accordance with the IUPAC rules of organic nomenclature [5]. The polymer is named in the usual style: poly(constitutional repeating unit).

Since double-strand polymers have no single, acyclic bonds, the CRU can be defined only by breaking rings. When rings are broken the following criteria are applied in decreasing order of priority:

Table 7: Examples of nomenclature of irregular single-strand organic polymers.

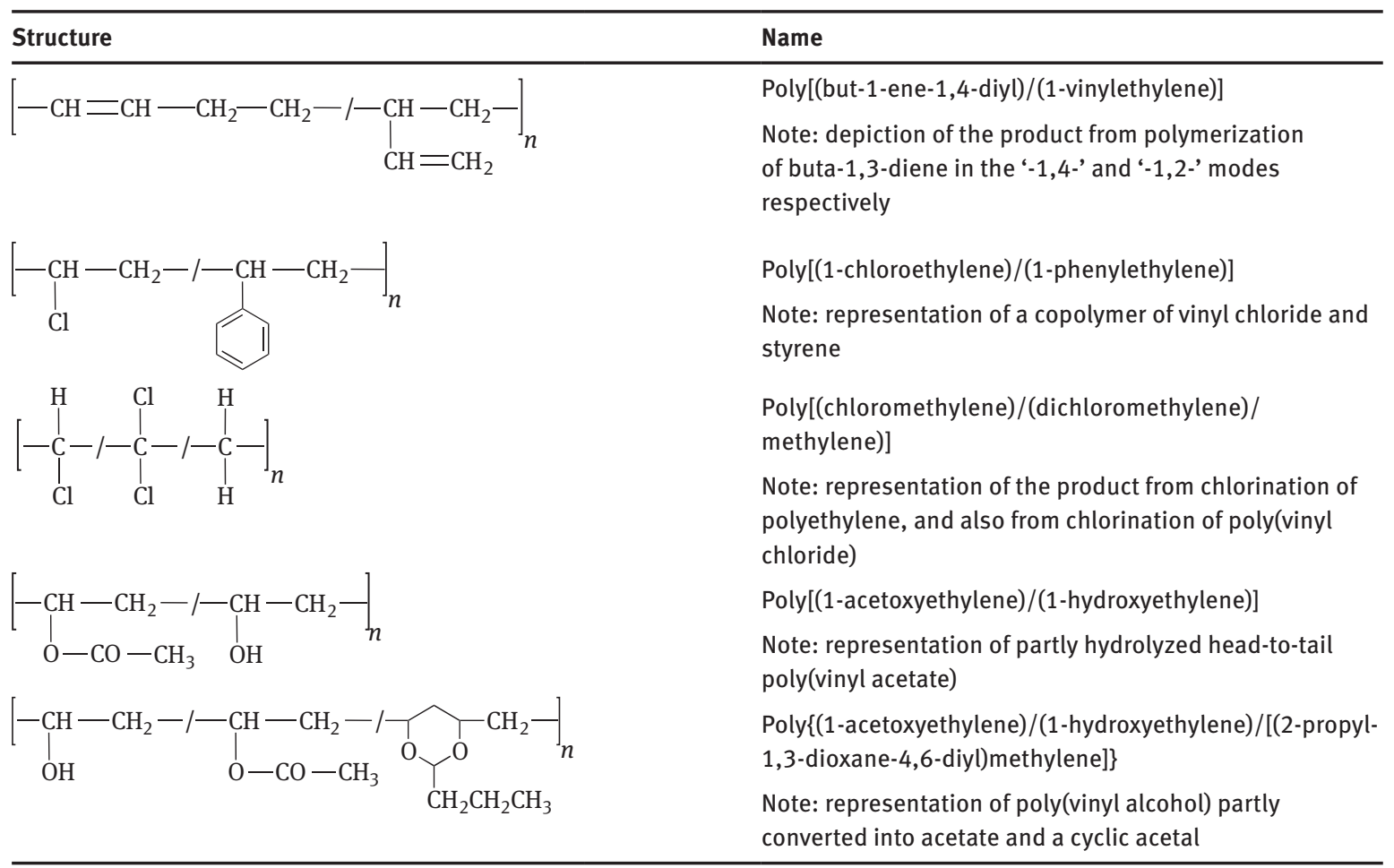


1. Minimize the number of free valences in the preferred CRU.

2. Maximize the number of most preferred heteroatoms in the remaining ring system.

3. Maintain intact the most preferred ring system.

Further decisions are based upon the following:

4. Ring system seniority.

5. Orientation of the CRU to assign the lowest free-valence locant at the lower left position of the structure.

6. Placement of any acyclic subunits on the right-hand side of the CRU formula.

The following three examples illustrate these rules.

Example 7: For the ladder polymer<smiles>CC1CC2CC3CC4CC(C)C(C)CC4CC3CC2C1</smiles>

comprising fused six-membered, saturated carbocycles, the preferred CRU is an acyclic subunit of four carbon atoms with four free valences, one at each atom. The lower left atom is assigned the lowest number.<smiles>CC1CCCCC1C</smiles>

The CRU is numbered as above: in this case it is anti-clockwise from the lower left position. Within the CRU name, the free-valence locants are placed immediately before the corresponding suffixes, as is now general practice in IUPAC nomenclature. They are always cited, complete with punctuation (commas and colon), in the following order and style:

$$
\text { lower left,upper left:upper right,lower right. }
$$

Thus, the name is poly(butane-1,4:3,2-tetrayl).

Example 8: The ladder polymer

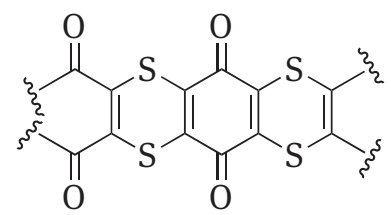

contains a heterocycle which alternates with a carbocycle. The heterocycle is senior to the carbocycle (see criterion $\mathbf{2}$ above). Therefore, the carbocycle is preferentially broken and the heterocycle is placed leftmost. The two groups resulting from the break of the carbocycle are placed to the right of the heterocyclic subunit (see criterion 6 above).

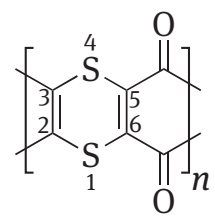


Thus, the name is poly(1,4-dithiine-2,3:5,6-tetrayl-5,6-dicarbonyl).

Example 9: The spiro polymer<smiles>CCCC1(CC)CCC2(CC1)OCC1(CO2)COC2(CCC3(CC2)OCC2(COC4(CCC5(CC4)OCC(COC)(COC(C)C)CO5)OC2)CO3)OC1</smiles>

contains two types of rings, namely two 1,3-dioxane rings (in opposing orientation) and a cyclohexane ring. The preferred CRU retains the two 1,3-dioxane rings, and the carbocycle is broken (see criterion 2 above). The acyclic fragments are placed to the right of the heterocyclic ring system (see criterion $\mathbf{6}$ above).

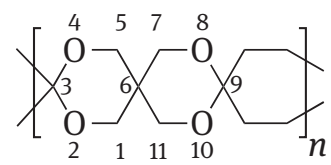

Thus, the name is poly(2,4,8,10-tetraoxaspiro[5.5]undecane-3,3:9,9-tetrayl-9,9-diethylene).

\section{Traditional names of polymers}

For many common substances, trivial names, not necessarily related to the chemical structures they represent, have been in use for many decades. For polymers, these names are usually referred to as traditional names. Examples of trivial names of divalent groups still permitted for use in structure-based nomenclature include ethylene, isophthaloyl, malonyl, oxalyl, phthaloyl, and terephthaloyl [12, 13]. Similarly, retained trivial names of monomers can be used in source-based nomenclature.

Further, because of their widespread use, a limited number of well-established traditional polymer names are retained outside the systems of source-based or structure-based nomenclature [8, 13]. Table 8 compares and contrasts structure-based, source-based, and retained traditional names for some common polymers.

\section{Abbreviations for polymer names [17]}

It is common practice in the area of polymer sciences to use abbreviations and acronyms (rather than numbers as labels as in other areas of chemistry) for both monomers and polymers, as well as for additives, modifiers, and fillers. IUPAC recommends that authors fully define each abbreviation the first time it appears in a document. IUPAC has also issued recommendations on how to best arrive at abbreviations for representing polymers [17].

\section{Polymer class names [18]}

Many publications (encyclopedias, handbooks, indexes, textbooks, etc.) discuss polymers under class names. These classes are not mutually exclusive; some are very specific, whereas others are more generic. Table 9 lists many of the terms commonly encountered in such publications. 
Table 8: Structure-based, source-based, and retained traditional names for some common polymers ${ }^{\mathrm{a}}[8,13]$.

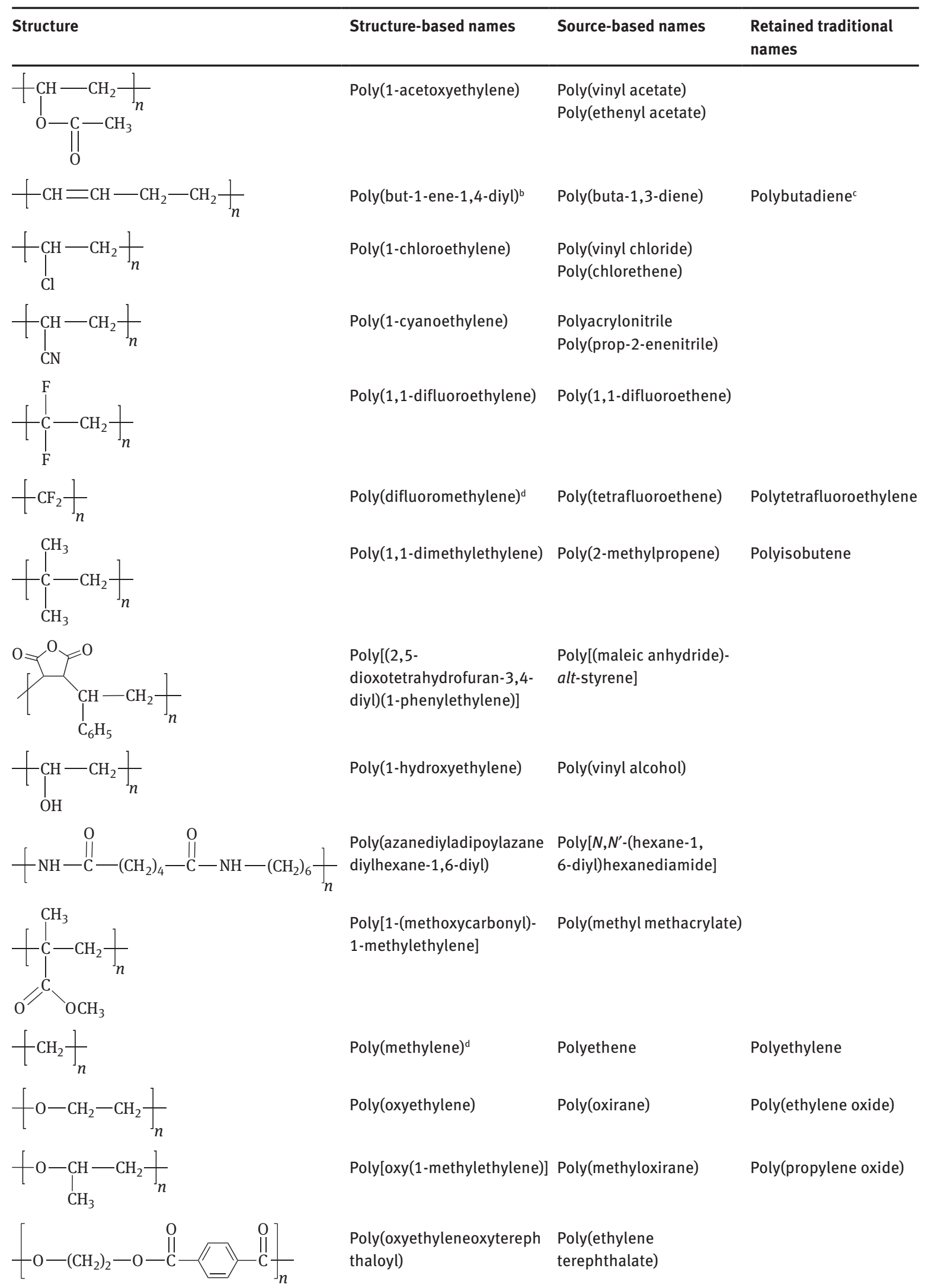


Table 8 (continued)

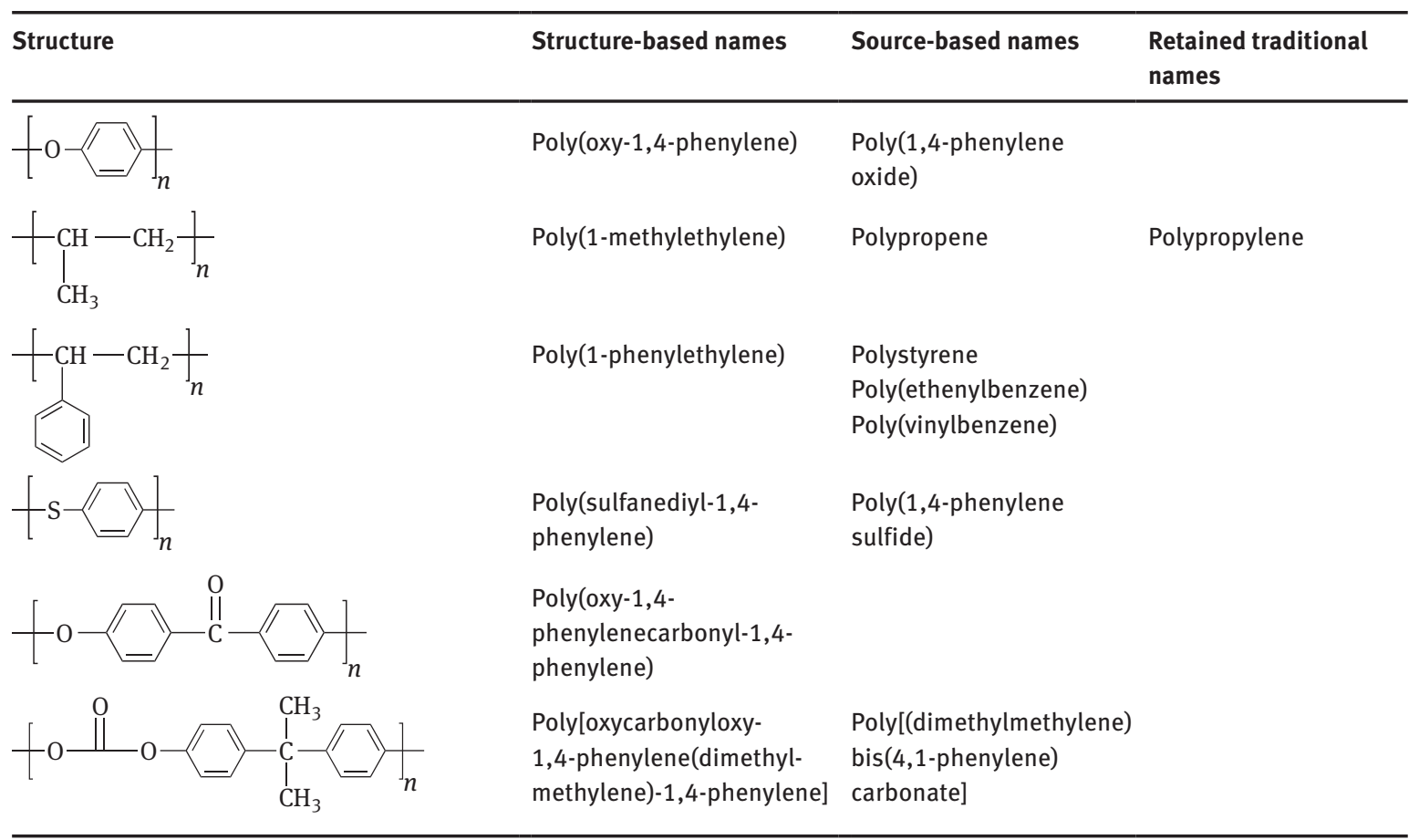

aThere is no 1:1-correlation between structure-based names, source-based names, and retained traditional names for polymers. 'This assumes polymerization of buta-1,3-diene in the '-1,4-' mode, for which the $\mathrm{CRU}$ is usually written $-\left[-\mathrm{CH}_{2}-\mathrm{CH}=\mathrm{CH}-\right.$ $\left.\mathrm{CH}_{2}-\right]_{n}-$. This is correct, but not the preferred $\mathrm{CRU}$, which is as shown in the Table. Similarly, the preferred CRU for isoprene polymerized in the '-1,4-' mode is $-\left[-\mathrm{C}\left(\mathrm{CH}_{3}\right)=\mathrm{CH}-\mathrm{CH}_{2}-\mathrm{CH}_{2}-\right]_{n}-$ and named poly(1-methylbut-1-ene-1,4-diyl).

'The traditional name polybutadiene should not be used if the structure of the polymer is known. In such circumstances the structure-based name should be used.

dStructure-based representations $-\left[-\mathrm{CH}_{2}-\right]_{n}-$ and $-\left[-\mathrm{CF}_{2}-\right]_{n}-$ are preferred for poly(methylene) and poly(difluoromethylene), respectively. However, because of past usage, and as an attempt to retain some similarity to the $\mathrm{CRU}$ formulae of homopolymers derived from other ethene derivatives, the $\mathrm{CRU}$ representations $-\left[-\mathrm{CH}_{2}-\mathrm{CH}_{2}-\right]_{n}-$ and $-\left[-\mathrm{CF}_{2}-\mathrm{CF}_{2}-\right]_{n}-$ are also acceptable.

Table 9: List of some commonly encountered polymer class names [18].

\begin{tabular}{llll}
\hline Acrylics & Polyarylenealkylenes & Polyisocyanurates & Polysilsesquioxanes \\
Alkyds & Polybenzimidazoles & Polyketones & Polysulfonamides \\
Amino polymers & Polybenzothiazoles & Polyolefins & Polysulfones \\
Aramids (=aromatic polyamides) & Polybenzoxazoles & Polyoxadiazoles & Polythiazoles \\
Epoxy polymers & Polybenzyls & Polyoxyalkylenes & Polythioalkylenes \\
Fluoropolymers & Polycarbodiimides & Polyoxyarylenes & Polythioarylenes \\
Phenolic polymers & Polycarbonates & Polyoxymethylenes & Polythioethers \\
Polyacetylenes & Polycarboranes & Polyoxyphenylenes & Polythiomethylenes \\
Polyalkenylenes & Polycarbosilanes & Polyphenylenes & Polythiophenylenes \\
Polyalkylenes & Polycyanurates & Polyphosphazenes & Polyureas \\
Polyalkynylenes & Polydienes & Polypyrroles & Polyurethanes \\
Polyamic acids & Polyesters & Polyquinolines & Polyvinyl acetals \\
Polyamides & Polyethers & Polyquinoxalines & Vinyl polymers \\
Polyamines & Polyhydrazides & Polysilanes & \\
Polyanhydrides & Polyimidazoles & Polysilazanes & \\
Polyarylenealkenylenes & Polyimides & Polysiloxanes & \\
\hline
\end{tabular}

${ }^{a}$ Often called epoxies, which is unacceptable.

bIncludes polyetherketones. 


\section{Membership of sponsoring bodies}

Membership of the Subcommittee on Polymer Terminology (until 2005, the Subcommittee on Macromolecular Terminology) during the preparation of these Recommendations (2008-2018) was as follows:

Chair: R. G. Jones (UK), 2006-2013; R. C. Hiorns (France), from 2014; Secretary: T. Kitayama (Japan), 2008-2009; R. C. Hiorns (France), 2010-2013; C. K. Luscombe (USA), 2014-2015; P. D. Topham (UK), from 2016; Members: R. Adhikari (Nepal); G. Allegra (Italy); M. Barón (Argentina); R. Boucher (UK); P. Carbone (UK); M. C. H. Chan (Malaysia); T. Chang (Korea); J. Chen (USA); C. Fellows (Australia); A. Fradet (France); C. F. O. Graeff (Brazil); K. Hatada (Japan); J. He (China); K.-H. Hellwich (Germany); M. Hess (Germany);

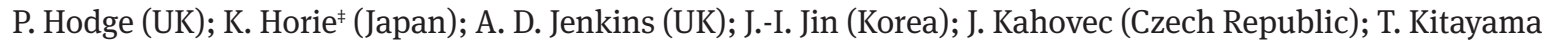
(Japan); P. Kratochvíl (Czech Republic); P. Kubisa (Poland); M. Malinconico (Italy); J. B. Matson (USA); E. Maréchal (France); S. V. Meille (Italy); I. Meisel (Germany); J. Merna (Czech Republic); W. V. Metanomski ${ }^{\ddagger}$ (USA); G. Moad (Australia); W. Mormann (Germany); T. Nakano (Japan), C. K. Ober (USA); S. Penczek (Poland); O. Phillipova (Russia); M. D. Purbrick (UK); G. Raos (Italy); L. P. Rebelo (Portugal); M. Rinaudo (France); G. T. Russell (New Zealand); C. dos Santos (Brazil); C. Scholz (USA); F. Schué (France); S. Słomkowski (Poland); R. F. T. Stepto ${ }^{\ddagger}(\mathrm{UK}) ;$ N. Stingelin (UK); A. Sturcova (Czech Republic); D. Tabak (Brazil); P. Théato (Germany); J.-P. Vairon (France); M. Vert (France); J. Vohlídal (Czech Republic); M. G. Walter (USA); E. S. Wilks (USA); W. J. Work (USA).

Membership of the IUPAC Polymer Division Committee for the period 2018-2019 is as follows: President: G. T. Russell (New Zealand); Vice President: C. K. Luscombe (USA); Secretary: M. G. Walter (USA); Titular Members: C. Fellows (Australia); R. C. Hiorns (France); R. Hutchinson (Canada); I. Lacík (Slovakia); N. Stingelin (UK); P. D. Topham (UK); Y. Yagci (Turkey); Associate Members: S. Beuermann (Germany); M. C. H. Chan (Malaysia); D. S. Lee (Korea); G. Moad (Australia); C. dos Santos (Brazil); P. Théato (Germany); National Representatives: R. Adhikari (Nepal); J. He (China); M. Hess (Germany); V. P. Hoven (Thailand); C.-S. Hsu (Taiwan); P. Mallon (South Africa); O. Philippova (Russia); M. Sawamoto (Japan); A. Sturcova (Czech Republic); Jan van Hest (Netherlands).

\section{References}

[1] Compendium of Polymer Terminology and Nomenclature (IUPAC Recommendations 2008) (the "Purple Book"), prepared for publication by R. G. Jones, J. Kahovec, R. F. T. Stepto, E. S. Wilks, M. Hess, T. Kitayama, W. V. Metanomski, with advice from A. Jenkins and P. Kratochvíl, RSC Publishing, Cambridge (UK), (2009). PDF on-line version: <https://iupac.org/project/ 2002-048-1-400>.

[2] IUPAC. Pure Appl. Chem. 84, 2167 (2012).

[3] IUPAC. Pure Appl. Chem. 80, 277 (2008).

[4] IUPAC. Pure Appl. Chem. 66, 2469 (1994).

[5] Nomenclature of Organic Chemistry, IUPAC Recommendations and Preferred Names 2013 (the "Blue Book"), prepared for publication by H. A. Favre, W. H. Powell, Royal Society of Chemistry, Cambridge (UK) (2013). HTML corrections and additions: <http://www.sbcs.qmul.ac.uk/iupac/bibliog/BBerrors.html>.

[6] Nomenclature of Inorganic Chemistry, IUPAC Recommendations 2005 (the "Red Book"), prepared for publication by N. G. Connelly, T. Damhus, R. M. Hartshorn, A. T. Hutton, RSC Publishing, Cambridge (UK) (2005).

[7] IUPAC. Pure Appl. Chem. 87, 1039 (2015).

[8] IUPAC. Pure Appl. Chem. 88, 1073 (2016).

[9] The word 'copolymer' is used in the literature to indicate a polymer containing two or more types of monomer. Use of the word 'bipolymer' for a polymer containing two types of monomer is sometimes used and this is in accord with the common use of 'terpolymer' for a polymer produced from three types of monomer, and 'quaterpolymer' (rather than tetrapolymer) for a polymer produced from four types of monomer, etc.

[10] IUPAC. Pure Appl. Chem. 57, 1427 (1985); reprinted as Chapter 19 in ref. 1.

${ }^{\ddagger}$ Deceased. 
[11] IUPAC. Pure Appl. Chem. 69, 2511 (1997); reprinted as Chapter 20 in ref. 1.

[12] IUPAC. Pure Appl. Chem. 74, 1921 (2002).

[13] IUPAC. Pure Appl. Chem. 89, 1695 (2017).

[14] This name corresponds strictly to a polymer composed entirely of $-\mathrm{O}-\mathrm{CH}\left(\mathrm{CH}_{3}\right)-\mathrm{CH}_{2}-$ units. This polymer is frequently called simply 'polyoxypropylene'. Use of the latter name is not recommended.

[15] IUPAC. Pure Appl. Chem. 66, 873 (1994); reprinted as Chapter 17 in ref. 1.

[16] IUPAC. Pure Appl. Chem. 65, 1561 (1993); reprinted as Chapter 16 in ref. 1.

[17] IUPAC. Pure Appl. Chem. 86, 1003 (2014).

[18] IUPAC. Pure Appl. Chem. 81, 1131 (2009). 